\title{
Correction to: The cosmopolitan engineering student: an analysis of a recruitment campaign for KTH Royal Institute of Technology in Stockholm
}

\author{
Patricia Kingdon ${ }^{1,2}$
}

Published online: 29 July 2019

(c) Springer Nature B.V. 2019

\section{Correction to: Int J Technol Des Educ (2018) 28:787-802 https://doi.org/10.1007/s10798-017-9405-4}

In the original publication of this article, the content under the subheading section "Facilitating better life conditions in developing countries" which comes under the main heading "Making the future better for humanity" was published incorrectly. Now the same has been updated in this correction.

In two of the twelve projects, students are starting or supporting enterprises in developing countries (Tanzania and Bolivia). One is Project 2, IT to Tanzania. This is a project where students develop a mobile phone application that combines a weather reporting service with a system to organize the rescue of fishermen on Lake Victoria in Tanzania. The other is Project 8, Business Development in Bolivia. This is a project with two separate aims: (a) support the development of an already existing enterprise, in the local wood industry, in Bolivia and (b) provide a learning experience for the two students running the project. Both these projects support the narrative of a desired engineering student, who acts as a 'saviour' by helping others, in this case citizens in Bolivia and Tanzania. The effect is that Bolivians and the Tanzanians are depicted as 'the other' - those in need of saving (e.g. Schneider et al. 2009). In the era of colonialism, 'the other' (those in need) was associated with savages. Naturally, the campaign does not depict citizens in developing countries as savages. Still, same a similar message is communicated in a blog post where a student writes about a two-week holiday trip to Venezuela. In the blog post, the student writes that 'During our stay we had two break-ins into our hotel room, and when reporting this to the local police, they did not know how to start the computer, so no report was written' (Ekenkrantz 2009). Another example of how the students are entwined in a trajectory associated with colonialism is seen in the presentation of Project 8, Business Development in Bolivia.

The original article can be found online at https://doi.org/10.1007/s10798-017-9405-4.

Patricia Kingdon

pkingdon@kth.se

1 School of Education and Communication in Engineering Science, Royal Institute of Technology, Stockholm, Sweden

2 Skogmursvägen 16 F, 80264 Gävle, Sweden 
Although the enterprise is developed in the wood industry, nothing is said in the project presentation about whether or not the enterprise meets Swedish standards for sustainability. The effect of this is that the project appears to be managed with an attitude of laissez-fairness that is reminiscent of the approach associated with colonialism; that is to say, natural recourses are endless and economic growth is good.

Publisher's Note Springer Nature remains neutral with regard to jurisdictional claims in published maps and institutional affiliations. 